\title{
Effect of Surgical Margin Width on Patterns of Recurrence among Patients Undergoing R0 Hepatectomy for T1 Hepatocellular Carcinoma: An International Multi-Institutional Analysis
}

\author{
Diamantis I. Tsilimigras ${ }^{1} \cdot$ Kota Sahara $^{1,2} \cdot$ Dimitrios Moris $^{1} \cdot$ J. Madison Hyer ${ }^{1} \cdot$ Anghela Z. Paredes $^{1}$. \\ Fabio Bagante ${ }^{1,3} \cdot$ Katiuscha Merath $^{1}$. Ayesha S. Farooq ${ }^{1}$. Francesca Ratti ${ }^{4}$. Hugo P. Marques ${ }^{5}$. Olivier Soubrane ${ }^{6}$. \\ Daniel Azoulay ${ }^{6} \cdot$ Vincent Lam $^{7}$. George A. Poultsides ${ }^{8} \cdot$ Irinel Popescu $^{9} \cdot$ Sorin Alexandrescu ${ }^{9} \cdot$ Guillaume Martel $^{10}$. \\ Alfredo Guglielmi ${ }^{3} \cdot$ Tom Hugh $^{11} \cdot$ Luca Aldrighetti $^{4} \cdot$ Itaru Endo $^{2} \cdot$ Timothy M. Pawlik $^{1}$ (I)
}

Received: 7 February 2019 / Accepted: 17 May 2019 / Published online: 26 June 2019

(C) 2019 The Society for Surgery of the Alimentary Tract

\begin{abstract}
Introduction Although a positive surgical margin is a known prognostic factor for recurrence, the optimal surgical margin width in the context of an R0 resection for early-stage hepatocellular carcinoma (HCC) is still debated. The aim of the current study was to examine the impact of wide $(\geq 1 \mathrm{~cm})$ versus narrow $(<1 \mathrm{~cm})$ surgical margin status on the incidence and recurrence patterns among patients with T1 HCC undergoing an R0 hepatectomy.

Methods Between 1998 and 2017, patients with T1 HCC who underwent R0 hepatectomy for stage T1 HCC were identified using an international multi-institutional database. Recurrence-free survival (RFS) was estimated, and recurrence patterns were examined based on whether patients had a wide versus narrow resection margins.

Results Among 404 patients, median patient age was 66 years (IQR: 58-73). Most patients $(n=326,80.7 \%)$ had surgical margin $<$ $1 \mathrm{~cm}$, while $78(19.3 \%)$ patients had a $\geq 1 \mathrm{~cm}$ margin. The majority of patients had early recurrences $(<24$ months) in both margin width groups (<1 cm: $70.3 \%$ vs $\geq 1 \mathrm{~cm}: 85.7 \%, p=0.141)$; recurrence site was mostly intrahepatic $(<1 \mathrm{~cm}: 77 \%$ vs $\geq 1 \mathrm{~cm}: 61.9 \%$, $p=0.169)$. The 1-, 3-, and 5-year RFS among patients with margin $<1 \mathrm{~cm}$ were $77 \%, 48.9 \%$, and $35.3 \%$ versus $81.7 \%$, 65.8\%, and $60.7 \%$ for patients with margin $\geq 1 \mathrm{~cm}$, respectively $(p=0.02)$. Among patients undergoing anatomic resection, resection margin did not impact RFS (3-year RFS: $<1 \mathrm{~cm}: 49.2 \% \mathrm{vs} \geq 1 \mathrm{~cm}: 58.9 \%, p=0.169)$, whereas in the non-anatomic resection group, margin width $\geq 1 \mathrm{~cm}$ was associated with a better 3-year RFS compared to margin $<1 \mathrm{~cm}(86.7 \%$ vs $47.3 \%, p=0.017)$. On multivariable analysis, margin $\geq 1 \mathrm{~cm}$ remained protective against recurrence $(\mathrm{HR}=0.50,95 \% \mathrm{CI} 0.28-0.89)$, whereas Child-Pugh $\mathrm{B}(\mathrm{HR}=2.13,95 \% \mathrm{CI}$ $1.09-4.15), \mathrm{AFP} \geq 20 \mathrm{ng} / \mathrm{mL}(\mathrm{HR}=1.71,95 \% \mathrm{CI} 1.18-2.48)$, and presence of microscopic lymphovascular invasion $(\mathrm{HR}=1.48$, 95\%CI 1.01-2.18) were associated with a higher hazard of recurrence.

Conclusion Resection margins $\geq 1 \mathrm{~cm}$ predicted better RFS among patients undergoing R0 hepatectomy for T1 HCC, especially small $(<5 \mathrm{~cm}) \mathrm{HCC}$. Although resection margin width did not influence outcomes after anatomic resection, wider margins were more important among patients undergoing non-anatomic liver resections.
\end{abstract}

Electronic supplementary material The online version of this article (https://doi.org/10.1007/s11605-019-04275-0) contains supplementary material, which is available to authorized users.

Timothy M. Pawlik

tim.pawlik@osumc.edu

1 Department of Surgery, The Ohio State University Wexner Medical Center, 395 W. 12th Ave., Suite 670, Columbus, OH, USA

2 Yokohama City University School of Medicine, Yokohama, Japan

3 Department of Surgery, University of Verona, Verona, Italy

4 Department of Surgery, Ospedale San Raffaele, Milan, Italy

5 Department of Surgery, Curry Cabral Hospital, Lisbon, Portugal
6 Department of Hepatobiliopancreatic Surgery, APHP, Beaujon Hospital, Clichy, France

7 Department of Surgery, Westmead Hospital, Sydney, Australia

8 Department of Surgery, Stanford University, Stanford, CA, USA

9 Department of Surgery, Fundeni Clinical Institute, Bucharest, Romania

10 Department of Surgery, University of Ottawa, Ottawa, Canada

11 Department of Surgery, The University of Sydney, School of Medicine, Sydney, Australia 
Keywords Margin $\cdot$ Recurrence $\cdot$ Patterns $\cdot$ R0 hepatectomy

\section{Introduction}

Hepatocellular carcinoma (HCC) ranks as one of the most prevalent malignancies worldwide with an increasing incidence over the last few decades. ${ }^{1,2}$ Surgery, in the form of either liver resection or transplantation, remains the mainstay of treatment for patients with resectable HCC. ${ }^{3,}{ }^{4}$ Despite the advances in surgical techniques, cumulative recurrence rates are still high, reaching up to $70-80 \%$ among patients undergoing resection for HCC. ${ }^{5}$ Recurrence is clearly multifactorial, yet the surgical margin is considered the traditional cornerstone of resection. Although a positive margin status has been associated with lower recurrence rates, ${ }^{4,5}$ the optimal surgical margin width in the context of R0 resection is still debated. For example, a few studies have reported that a resection margin smaller than $1 \mathrm{~cm}$ was an adverse prognostic factor for recurrence. ${ }^{6-8}$ Other investigators have argued that a $0.5-$ to $1-\mathrm{cm}$ surgical margin does not increase the risk for recurrence and should be considered an adequate margin for resection of small-size tumors $(<5 \mathrm{~cm}){ }^{9}$ In contrast, a recent meta-analysis noted that a wide surgical margin $(\geq 1 \mathrm{~cm})$ was associated with an improved prognosis among patients undergoing resection for HCC compared with a narrow margin $(<$ $1 \mathrm{~cm}) .{ }^{10}$ As such, no current consensus exists regarding the optimal margin width for curative-intent hepatectomy.

In addition, patterns of $\mathrm{HCC}$ recurrence relative to surgical margin width are also poorly understood. Of note, intrahepatic metastases usually occur early after surgery, whereas multicentric occurrence is usually observed after a longer amount of time following hepatectomy. ${ }^{11}$ The effect of margin width on recurrence patterns has not been examined to date, with only one small study suggesting that patterns of recurrence (i.e., intra- or extrahepatic, early or late recurrence) may not be influenced by the extent of surgery. ${ }^{12}$ Nevertheless, narrow margins have been suggested to increase the risk of leaving "micro-metastases" given that HCC may track along the portal triad. The objective of the current study was to determine the effect of surgical margin width on recurrence after resection for HCC. Specifically, we sought to examine whether a narrow $(<1 \mathrm{~cm})$ versus a wide $(\geq 1 \mathrm{~cm})$ surgical margin impacted the incidence of recurrence, as well as define patterns of recurrence. In addition, clinical and pathological factors associated with recurrence following R0 hepatectomy for solitary tumors without macrovascular invasion were identified.

\section{Materials and Methods}

\section{Study Population and Data Collection}

Patients who underwent curative-intent R0 hepatectomy for histologically proven T1 HCC (solitary HCC without macroscopic vascular invasion) between 1998 and 2017 were identified using an international multi-institutional database. Patients were treated at 1 of 11 following participating institutions: the Ohio State University Wexner Medical Center, Columbus, OH, USA; Yokohama City University School of Medicine, Yokohama, Japan; University of Verona, Verona, Italy; Ospedale San Raffaele, Milano, Italy; Curry Cabral Hospital, Lisbon, Portugal; APHP, Beaujon Hospital, Clichy, France; Westmead Hospital, Sydney, Australia; Stanford University, Stanford, CA, USA; Fundeni Clinical Institute, Bucharest, Romania; University of Ottawa, Ottawa, Canada; The University of Sydney, School of Medicine, Sydney, Australia. Data on surgical margin width were collected based on pathological examination of the resected HCC. Patients were followed and outcomes were recorded in a prospectively maintained multi-institutional database. Patients who had R1/ R2 hepatectomy, multiple tumors, and/or macroscopic vascular invasion were excluded from this analysis. The study was approved by the Institutional Review Boards of all participating institutions.

\section{Variables and Outcomes of Interest}

The primary outcome was recurrence-free survival (RFS); RFS was defined as the time interval between the date of hepatectomy and the date of disease relapse or last followup. The secondary outcome was overall survival (OS); OS was defined as the time interval between the date of hepatectomy and the date of death or last follow-up. The primary independent variable was surgical margin width identified after pathological examination of the resected tumor. Demographic and clinical data included age, sex, race, Charlson comorbidity score (CCS), history of cirrhosis, hepatitis $\mathrm{B}$ virus (HBV)/hepatitis $\mathrm{C}$ virus (HCV) infection, ChildPugh liver function, grade type of surgical resection (i.e., anatomic or non-anatomic), laboratory values (i.e., a-fetoprotein (AFP), alanine aminotransferase (ALT), aspartate aminotransferase (AST), gamma-glutamyl transferase (GGT)), tumor grade, tumor size, pathologic lymphovascular invasion, and liver capsule involvement. In addition, patterns of recurrence, such as recurrence site (intrahepatic, extrahepatic), type 
(single, multiple), size, and early recurrence were examined. Local recurrence was defined as relapse in the nearest surgical margin; early recurrence was defined as disease relapse within 24 months after hepatectomy.

\section{Statistical Analysis}

Descriptive statistics were presented as median (interquartile range [IQR]) and frequency (\%) for continuous and categorical variables, respectively. Bivariate analyses included Wilcoxon rank-sum test for continuous and chi-squared test or Fisher's exact test for categorical variables, as appropriate. Bivariate survival analyses were performed using the log-rank test and presented using Kaplan-Meier curves. Variables significant on bivariate analysis ( $p$ value $<0.05$ ) were entered into the multivariable model. Multivariable survival analyses were performed using Cox proportional hazards regression analysis. The level of statistical significance was set at $\alpha=$ 0.05. All analyses were performed using SPSS, version 25 (IBM Corp., Armonk, NY, USA).

\section{Results}

\section{Patient Characteristics}

Between 1998 and 2017, a total of 404 patients met the inclusion criteria and were included in the analytic cohort (Fig. 1). Overall, median patient age was 66 years (IQR: 58-73), and most patients were male $(n=299,74.2 \%)$, white $(n=185$,
59.1\%), and had a median Charlson comorbidity score of 5 (IQR 4-6). History of cirrhosis and chronic alcoholism was prevalent in $36.7 \%(n=148)$ and $23.7 \%(n=94)$ of patients, respectively. Roughly one-fourth and one-third of patients had a history of HBV $(n=93,23 \%)$ or HCV infection $(n=117$, $29 \%$ ), respectively. Median HCC size was $4.3 \mathrm{~cm}$ (IQR: $3-8$ ). The majority of patients were Child-Pugh A $(n=274,94.5 \%)$, had well/moderately differentiated tumors $(n=316,81.5 \%)$, and had undergone anatomic resection for HCC $(n=320$, $79.2 \%)$. On histological examination, $31.8 \%(n=118 / 371)$ of patients had lymphovascular invasion, whereas liver capsule involvement was present in $31.4 \%(n=88 / 280)$ of the patients (Table 1).

Of the 404 patients, $326(80.7 \%)$ patients had a surgical margin $<1 \mathrm{~cm}$, while $78(19.3 \%)$ patients had $\geq 1 \mathrm{~cm}$. At baseline, the two groups were different only in terms of sex and history of $\mathrm{HCV}$ infection; compared to margin group < $1 \mathrm{~cm}$, margin group $\geq 1 \mathrm{~cm}$ had fewer males $(65.4 \%$ vs 76.3 , $p=0.048)$, and a lower incidence of HCV infection (16.7\% vs $32 \%, p=0.007$ ). All other variables examined, including age, race, CCS, cirrhosis, history of chronic alcoholism, HBV infection, tumor size and grade, Child-Pugh class, type of resection, AFP, ALT, AST and GGT values, microscopic lymphovascular invasion, and liver capsule involvement were similar between the two groups (Table 1).

\section{Recurrence Patterns}

The median follow-up period was 28.5 months (IQR 11.653.5 months). The recurrence patterns were similar between
Fig. 1 Flowchart of the selection of patients included in the analytic cohort

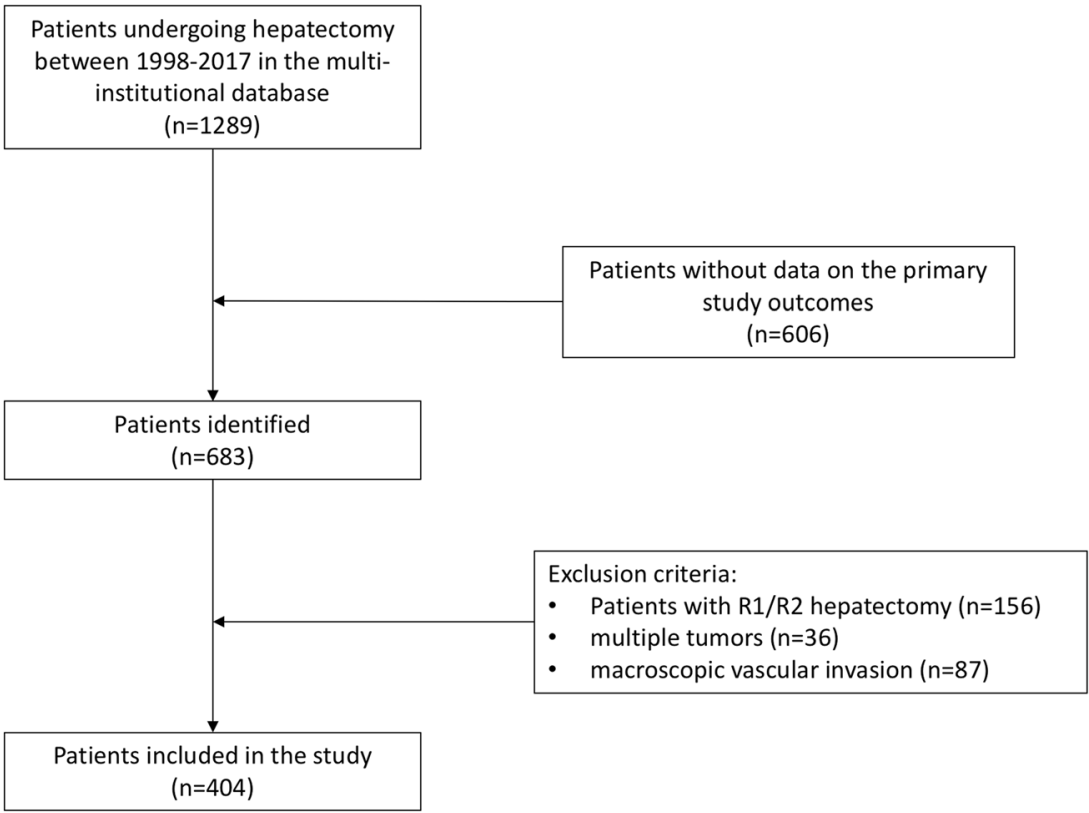


Table 1 Patient and tumor characteristics

\begin{tabular}{|c|c|c|c|c|}
\hline Variables & $\begin{array}{l}\text { Total } \\
(n=404)\end{array}$ & $\begin{array}{l}<1 \mathrm{~cm}(n=326, \\
80.7 \%)\end{array}$ & $\begin{array}{l}\geq 1 \mathrm{~cm}(n=78, \\
19.3 \%)\end{array}$ & $\begin{array}{l}p \\
\text { value }\end{array}$ \\
\hline Age, years & $66(58,73)$ & $66(58,73)$ & $65(57,73)$ & 0.72 \\
\hline Gender & & & & 0.048 \\
\hline Female & $104(25.8 \%)$ & $77(23.7 \%)$ & $27(34.6 \%)$ & \\
\hline Male & $299(74.2 \%)$ & $248(76.3 \%)$ & $51(65.4 \%)$ & \\
\hline Race & & & & 0.512 \\
\hline White & $185(59.1 \%)$ & $147(58.1 \%)$ & $38(63.3 \%)$ & \\
\hline AA & $34(10.9 \%)$ & $26(10.3 \%)$ & $8(13.3 \%)$ & \\
\hline Other & $94(30 \%)$ & $80(31.6 \%)$ & $14(23.4 \%)$ & \\
\hline $\mathrm{CCS}$ & $5(4,6)$ & $5(4,6)$ & $5(4,6)$ & 0.57 \\
\hline Cirrhosis & & & & 0.926 \\
\hline No & $255(63.3 \%)$ & $206(63.4 \%)$ & $49(62.8 \%)$ & \\
\hline Yes & $148(36.7 \%)$ & $119(36.6 \%)$ & $29(37.2 \%)$ & \\
\hline Chronic alcoholism & & & & 0.10 \\
\hline No & $302(76.3 \%)$ & $237(74.5 \%)$ & $65(83.3 \%)$ & \\
\hline Yes & $94(23.7 \%)$ & $81(25.5 \%)$ & $13(16.7 \%)$ & \\
\hline HBV infection & & & & 0.4 \\
\hline No & $306(76.7 \%)$ & $249(77.6 \%)$ & $57(73.1 \%)$ & \\
\hline Yes & $93(23 \%)$ & $72(22.4 \%)$ & $21(26.9 \%)$ & \\
\hline HCV infection & & & & 0.007 \\
\hline No & $286(71 \%)$ & $221(68 \%)$ & $65(83.3 \%)$ & \\
\hline Yes & $117(29 \%)$ & $104(32 \%)$ & $13(16.7)$ & \\
\hline Tumor size, $\mathrm{cm}$ & $4.3(3,8)$ & $4(3,8)$ & $4.5(3,8)$ & 0.672 \\
\hline Tumor grade & & & & 0.504 \\
\hline Well & $93(24 \%)$ & $74(23.6 \%)$ & $19(18 \%)$ & \\
\hline Mod & $223(57.5 \%)$ & $178(56.9 \%)$ & $45(60 \%)$ & \\
\hline Poor & $68(17.5 \%)$ & $57(18.2 \%)$ & $11(14.7 \%)$ & \\
\hline Undif & $4(1 \%)$ & $4(1.3 \%)$ & $0(0 \%)$ & \\
\hline Child-Pugh class & & & & 0.516 \\
\hline A & $274(94.5 \%)$ & $223(94.9 \%)$ & $51(92.7 \%)$ & \\
\hline $\mathrm{B}$ & $16(5.5 \%)$ & $12(5.1 \%)$ & $4(7.3 \%)$ & \\
\hline Type of resection & & & & 0.58 \\
\hline $\mathrm{AR}$ & $320(79.2 \%)$ & $260(79.8 \%)$ & $60(76.9 \%)$ & \\
\hline NAR & $84(20.8 \%)$ & $66(20.2 \%)$ & $18(23.1 \%)$ & \\
\hline AFP, ng/mL & $8(3,61)$ & $8(3,97)$ & $10(3,143)$ & 0.79 \\
\hline ALT, U/L & $41(26,68)$ & $42(26,67)$ & $39(27,75)$ & 0.70 \\
\hline AST, U/L & $41(28,61)$ & $40(28,62)$ & $43.5(30,62)$ & 0.50 \\
\hline GGT, U/L & $80(48,156)$ & $79(48,155)$ & $83(42,161)$ & 0.76 \\
\hline $\begin{array}{l}\text { Pathologic lymphovascular } \\
\text { invasion }\end{array}$ & $253(68.2 \%)$ & $205(69.5 \%)$ & $48(63.2 \%)$ & 0.29 \\
\hline No & $118(31.8 \%)$ & $90(30.5 \%)$ & $28(36.8 \%)$ & \\
\hline \multicolumn{5}{|l|}{ Yes } \\
\hline Liver capsule involvement & & & & 0.14 \\
\hline No & $192(68.6 \%)$ & $180(69.8 \%)$ & $12(54.5 \%)$ & \\
\hline Yes & $88(31.4 \%)$ & $78(30.2 \%)$ & $10(45.5 \%)$ & \\
\hline
\end{tabular}

$A A$ African American, $C C S$ Charlson Comorbidity Score, $H B V$ hepatitis B virus, $H C V$ hepatitis $\mathrm{C}$ virus, $A R$ anatomical resection, $N A R$ non-anatomical resection, $A F P$ a-fetoprotein, $A L T$ alanine aminotransferase, $A S T$ aspartate aminotransferase, GGT gamma-glutamyl transferase; Italics denote statistical significance 
the $<1 \mathrm{~cm}$ and $>1 \mathrm{~cm}$ margin groups (Table 2 ). The majority of patients had early recurrence $(<24$ months) in both groups ( $<1 \mathrm{~cm}: 70.3 \%$ vs $\geq 1 \mathrm{~cm}: 85.7 \%, p=0.141)$. The incidence of local recurrence was $7.1 \%$ among patients with resection margin $<1 \mathrm{~cm}$ versus $4.8 \%$ among patients with a margin $\geq$ $1 \mathrm{~cm}(p=1.0)$. When recurrence occurred, it was mostly intrahepatic in both groups $(<1 \mathrm{~cm}: 77 \%$ vs $\geq 1 \mathrm{~cm}: 61.9 \%$, $p=0.169$ ). Recurrences in the resection margin $<1 \mathrm{~cm}$ group involved single tumors (single $56.8 \%$, multiple $43.2 \%$ ), while multiple tumor recurrences were slightly more common in margin $\geq 1 \mathrm{~cm}$ group (single $41.7 \%$, multiple $58.3 \%$ ) ( $p=$ $0.314)$. Size of the recurrent tumors was similar between the two groups (margin $<1 \mathrm{~cm}$; median tumor size: $2 \mathrm{~cm}$, IQR $1.5-3.1$ vs margin $\geq 1 \mathrm{~cm} ; 2.1 \mathrm{~cm}$, IQR $1.2-3.6, p=0.92$ ).

\section{Recurrence-Free and Overall Survival}

Overall 1-, 3-, and 5-year RFS among patients with a surgical margin $<1 \mathrm{~cm}$ were $77 \%, 48.9 \%$, and $35.3 \%$ versus $81.7 \%$, $65.8 \%$, and $60.7 \%$ among patients with margin $\geq 1 \mathrm{~cm}$, respectively (log-rank $p=0.02$, Fig. 2). Similarly, 5-year OS was worse among patients with a surgical margin $<1 \mathrm{~cm}$ versus patients with margin $\geq 1 \mathrm{~cm}(60.2 \%$ vs $74 \%, p=0.047)$. Of note, when stratified by tumor size, patients with resection margin $\geq 1 \mathrm{~cm}$ had better RFS only among patients undergoing resection for tumors $<5 \mathrm{~cm}$ (5-year RFS; $<1 \mathrm{~cm}$ : $39.6 \%$ vs $\geq 1 \mathrm{~cm}: 70.3 \%, \log$-rank $p=0.022)$; in contrast, among patients with larger tumors $(\geq 5 \mathrm{~cm})$, no difference in RFS was detected relative to surgical margin width (5-year RFS; $<1 \mathrm{~cm}: 29.4 \%$ vs $\geq 1 \mathrm{~cm}: 49.8 \%$, log-rank $p=0.263$ ). Anatomic resection was performed among 79.8\% $(n=260)$ of patients who had a margin $<1 \mathrm{~cm}$ versus $76.9 \%(n=60)$ among patients with a margin $\geq 1 \mathrm{~cm}(p=0.58)$. After stratifying by extent of resection (i.e., anatomic, non-anatomic), margin width $(<1 \mathrm{~cm}$ vs $\geq 1 \mathrm{~cm})$ did not impact RFS among patients undergoing an anatomic resection for HCC (1-year
RFS $76.2 \%$ vs $80.2 \%$, 2-year RFS: $58.9 \%$ vs $63.4 \%$, 3-year RFS $49.2 \%$ vs $58.9 \%$; respectively, log-rank $p=0.169$, Supplemental Fig. 1a). In contrast, among patients with nonanatomic resection, margin width $\geq 1 \mathrm{~cm}$ was associated with a better 3-year RFS compared with a margin width $<1 \mathrm{~cm}$ (3year RFS: $86.7 \%$ vs $47.3 \%$, log-rank $p=0.017$, Supplemental Fig. 1b). Of note, pathologic lymphovascular invasion was present in $30.5 \%(n=90)$ versus $36.8 \%(n=28)$ of patients with a resection margin $<1 \mathrm{~cm}$ and $>1 \mathrm{~cm}$, respectively $(p=$ $0.29)$. Among patients with lymphovascular invasion, margin status ( $<1 \mathrm{~cm}$ vs $\geq 1 \mathrm{~cm}$ ) did not impact RFS (3-year RFS: $36 \%$ vs $48.1 \%, p=0.42$, Supplemental Fig. 2a); in contrast, among patients without lymphovascular invasion, margin $\geq$ $1 \mathrm{~cm}$ was associated with better 3-year RFS $(77.3 \%$ vs $54.7 \%$, $p=0.017$, Supplemental Fig. 2b).

On multivariable analysis, after controlling for competing risk factors, margin width $\geq 1 \mathrm{~cm}$ remained protective against recurrence (referent $<1 \mathrm{~cm}$ : $\mathrm{HR}=0.50,95 \% \mathrm{CI} 0.28-0.89$, $p=0.017$ ) (Table 3). In contrast, Child-Pugh B (referent A: $\mathrm{HR}=2.13,95 \% \mathrm{CI} 1.09-4.15, p=0.027), \mathrm{AFP} \geq 20 \mathrm{ng} / \mathrm{mL}$ (referent <20: $\mathrm{HR}=1.71,95 \% \mathrm{CI} 1.18-2.48, p=0.005$ ), ALT $\geq 40 \mathrm{U} / \mathrm{L}$ (referent $<40$ : HR $=1.53,95 \%$ CI 1.05-2.23, $p=0.027$ ), and microscopic lymphovascular invasion (HR = $1.48,95 \%$ CI $1.01-2.18, p=0.044)$ were associated with a higher hazard of recurrence. Tumor size $\geq 5 \mathrm{~cm}$ was also associated with increased risk of recurrence on bivariable analysis (referent $<5 \mathrm{~cm}$ : HR $=1.52,95 \% \mathrm{CI} 1.12-2.06, p=$ 0.007).

\section{Discussion}

Surgery remains the mainstay of treatment and the best chance for cure among patients diagnosed with $\mathrm{HCC} .{ }^{4}$ Nevertheless, recurrence rates can be as high as $70 \%$ after curative-intent hepatectomy. ${ }^{13}$ While R0 resection may improve long-term
Table 2 Recurrence patterns stratified by surgical margin width

\begin{tabular}{lccc}
\hline Variables & $<1 \mathrm{~cm}(n=145,44.5 \%)$ & $\geq 1 \mathrm{~cm}(n=21,26.9 \%)$ & $p$ value \\
\hline $\begin{array}{l}\text { Local recurrence } \\
\text { Recurrence site }\end{array}$ & $9(7.1 \%)$ & $1(4.8 \%)$ & 1.0 \\
Intrahepatic & $97(77 \%)$ & $13(61.9 \%)$ & 0.169 \\
Extrahepatic & $18(14.3 \%)$ & $3(14.3 \%)$ & \\
Both & $11(8.7 \%)$ & $5(23.8 \%)$ & 0.314 \\
Recurrence type & & & \\
Single & $67(56.8 \%)$ & $5(41.7 \%)$ & 0.92 \\
Multiple & $51(43.2 \%)$ & $7(58.3 \%)$ & 0.141 \\
Recurrence size, cm & $2(1.5,3.1)$ & $2.1(1.2,3.6)$ & \\
Time to recurrence, months & & $18(85.7 \%)$ & \\
$<24$ & $102(70.3 \%)$ & $3(14.3 \%)$ & \\
$\geq 24$ & $43(29.7 \%)$ & & \\
\hline
\end{tabular}


Fig. 2 Kaplan-Meier curve demonstrating the differences in recurrence-free survival among patients with $<1 \mathrm{~cm}$ and $\geq 1 \mathrm{~cm}$ resection margin

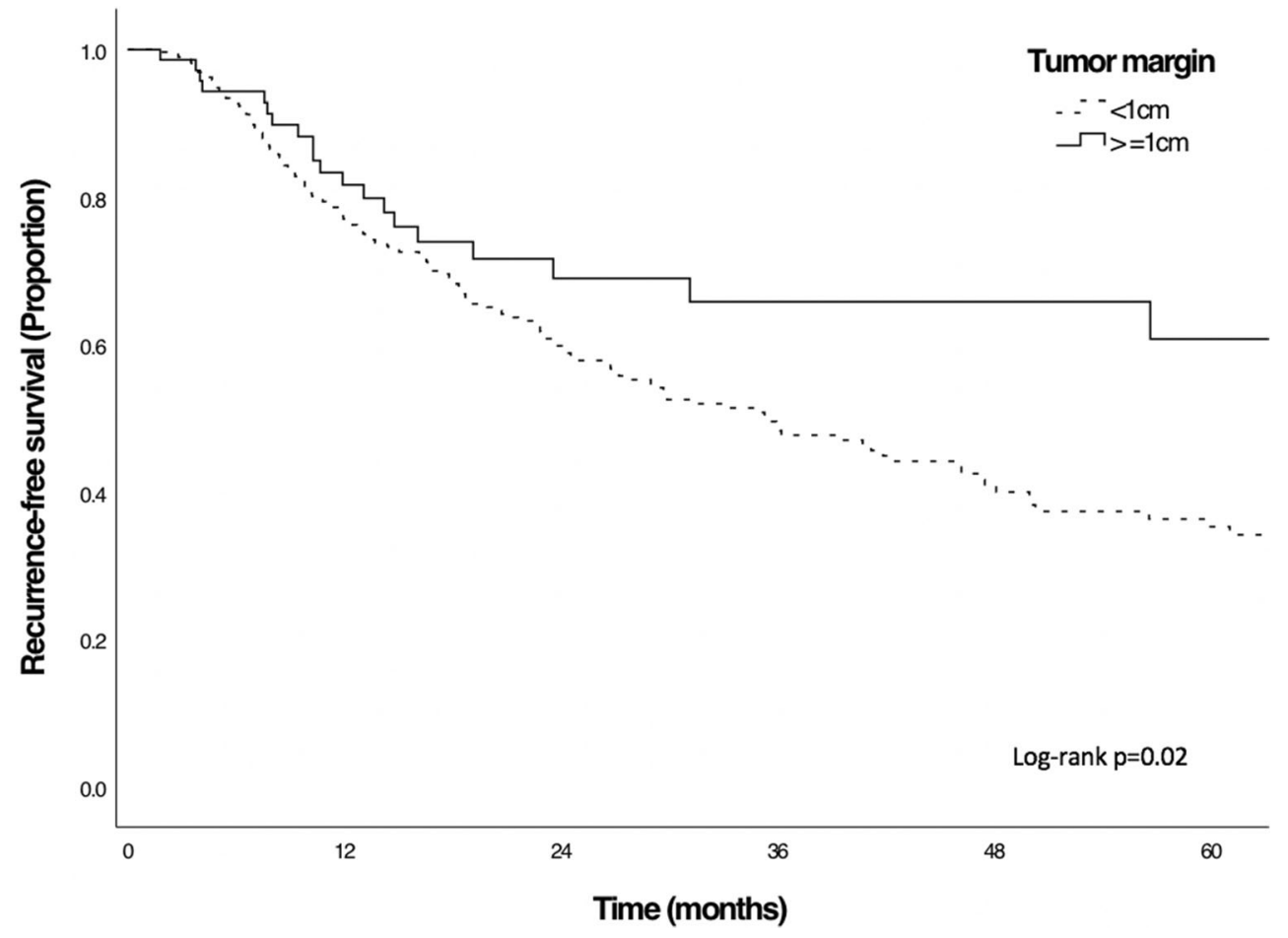

outcomes, the extent of surgical margin width that may be associated with the best outcomes following surgical treatment remains a subject of debate. ${ }^{8,9,14}$ Narrow margins could potentially increase the chances of recurrence as "micrometastases" may be present in the tumor periphery. ${ }^{15}$ On the other hand, preserving the maximum possible liver parenchyma after resection is of paramount importance for patient recovery and overall survival. ${ }^{15,16}$ The current study was important because we specifically examined the effect of resection margin on the incidence of recurrence, as well as patterns of recurrence, among patients undergoing R0 hepatectomy for T1 HCC utilizing an international multi-institutional database. Of note, wide-resection margins $(\geq 1 \mathrm{~cm})$ were associated with better RFS compared with narrow margins $(<1 \mathrm{~cm})$. This effect was more pronounced among patients undergoing resection for small $(<5 \mathrm{~cm}) \mathrm{HCC}$. Also, recurrences in both groups were largely intrahepatic and most often occurred within 24 months following R0 hepatectomy. Perhaps of more interest, there were differences in the effect of margin width based on the type of resection (i.e., anatomic, non-anatomic) and the presence of pathologic lymphovascular invasion. In particular, among patients undergoing anatomic resection, wide-resection margin was not associated with RFS, whereas among patients who underwent a non-anatomic resection, wider margins were associated with a lower recurrence risk. In addition, wide surgical margins were associated with lower recurrence when microscopic lymphovascular invasion was absent; in contrast, RFS was worse overall in the presence of lymphovascular invasion and there was no effect of margin width.
Several studies have previously examined the relationship between resection margin and the recurrence. ${ }^{8,9,} 14$ In one study from Taiwan, Lee et al. compared long-term outcomes of patients stratified by margin width (i.e., 1-5, 6-10 and > $10 \mathrm{~mm}){ }^{14}$ The authors noted no difference in 1-, 3-, and 5year RFS ( $p=0.354)$ and OS $(p=0.073)$ stratified by different margin widths; however, patients in the wide margin group experienced more postoperative complications $(p=0.020){ }^{14}$ Other studies have also demonstrated that a $0.5-$ to $1-\mathrm{cm}$ surgical margin width did not increase the risk for recurrence and suggested that this was acceptable for the resection of smallsize tumors $(<5 \mathrm{~cm}) .{ }^{9}$ In a more rigorous prospective randomized trial, Shi et al. reported that a resection margin that aimed a gross margin width of $2 \mathrm{~cm}$ decreased recurrence rates and increased OS compared with a gross resection margin of $1 \mathrm{~cm} .{ }^{8}$ Interestingly, this difference was more pronounced among patients who had an $\mathrm{HCC}<2 \mathrm{~cm} .{ }^{8}$ In the current study, we used an international multi-institutional database to examine patients with early T1 HCC. We noted that a resection margin $\geq 1 \mathrm{~cm}$ was associated with a better RFS versus a $<$ 1-cm margin (5-year RFS: $60.7 \%$ vs $35.3 \%, p=0.02$ ); the difference in RFS based on margin width persisted on multivariable analysis after controlling for competing risk factors (HR $=0.50,95 \% \mathrm{CI} 0.28-0.89)$. Importantly, the effect of resection margin was more pronounced among patients undergoing resection for small $(<5 \mathrm{~cm}) \mathrm{HCC}$, whereas for larger tumors $(\geq 5 \mathrm{~cm})$, the difference in RFS did not reach statistical significance. Whereas most previous studies suffered from heterogeneity and variations in the selection of patients, ${ }^{8}$ the 
two margin width groups in the current study were similar with regard to baseline characteristics except for sex and history of HCV infection. Consistent with our findings, a recent meta-analysis also noted an improved OS and RFS among patients undergoing hepatectomy who had wide $(\geq 1 \mathrm{~cm})$ versus narrow surgical margins $(<1 \mathrm{~cm}) .{ }^{10}$ Collectively, these data strongly suggest that a wide surgical margin may be associated with improved outcomes for patients undergoing hepatectomy for T1 HCC, especially for small $(<5 \mathrm{~cm}) \mathrm{HCC}$.

The importance of surgical margins has been demonstrated for other primary liver malignancies as well. ${ }^{15}$ For example, in a multi-institutional analysis of 584 patients undergoing resection for intrahepatic cholangiocarcinoma, Spolverato et al. reported that compared with a tumor-free margin $\geq 1$, a margin of 5-9 $\mathrm{mm}, 1-4 \mathrm{~mm}$, and positive margin were associated with lower OS and RFS (p-trend <0.001). ${ }^{17}$ Similarly, margin status rather than extent of hepatectomy has been demonstrated to influence outcomes among patients treated for gallbladder cancer. ${ }^{18}$ Although a negative margin is undoubtedly recognized as an adverse prognostic factor, $6,7,19$ the latest European Association for the Study of the Liver (EASL) HCC $(2018)^{3}$ and the American Association for the Study of Liver Diseases $(2018)^{4}$ guidelines do not specifically refer to the optimal margin width for patients undergoing hepatectomy for $\mathrm{HCC}$ in the context of a $\mathrm{R} 0$ resection. According to the EASL HCC guidelines (2018), an anatomic resection should be the preferred surgical approach provided that the patient has an adequate future liver remnant. ${ }^{3}$ In the current study, the percentage of patients undergoing anatomic resection was similar between the two margin width groups ( $79.8 \%$ vs $76.9 \%, p=0.58$ ). However, anatomic resection did not predict better outcomes relative to RFS (HR $=1.16$, 95\% CI 0.79 1.70). Perhaps more interesting, surgical margin width did not affect RFS in the context of an anatomic resection, suggesting that a minimum resection margin was enough when anatomic resection was performed. Indeed, for an anatomic resection of liver, Glisson pipelines are ligated and cut off in advance. ${ }^{20}$ In turn, more microvascular invasive lesionsthought to be strongly correlated with disease relapse - can theoretically be removed regardless of surgical margins when liver parenchyma is dissected. ${ }^{20,}{ }^{21}$ In contrast, a previous report noted that, in the case of non-anatomic resections, a wider surgical margin should be considered approapriate. ${ }^{19}$

Apart from the surgical margin, several other factors have been identified as prognostic of recurrence. In particular, presence of microvascular invasion, cirrhosis, Child-Pugh B or C class, need for transfusion, and HCC rupture ${ }^{22-24}$ have been demonstrated to increase risk of recurrence. The current study confirmed these results as patients with Child-Pugh B liver function were twice as likely to experience a recurrence $(\mathrm{HR}=2.13, p=0.027)$, while patients with microscopic lymphovascular invasion had almost 50\% higher hazards of recurrence $(\mathrm{HR}=1.48,1.01-2.18)$ compared with patients
Table 3 Bivariable and multivariable analysis of recurrence

\begin{tabular}{|c|c|c|c|c|}
\hline \multirow[t]{2}{*}{ Variable } & \multicolumn{2}{|l|}{ Bivariable } & \multicolumn{2}{|l|}{ Multivariable } \\
\hline & HR (95\%CI) & $p$ value & HR $(95 \% \mathrm{CI})$ & $p$ value \\
\hline \multicolumn{5}{|c|}{ Margin group, cm } \\
\hline$<1$ & ref & & ref & \\
\hline$\geq 1$ & $0.58(0.37-0.92)$ & 0.021 & $0.50(0.28-0.89)$ & 0.017 \\
\hline \multicolumn{5}{|l|}{$\overline{\text { Age, }}$ years } \\
\hline$<65$ & ref & & & \\
\hline$>65$ & $1.01(0.74-1.36)$ & 0.988 & - & - \\
\hline \multicolumn{5}{|l|}{ Gender } \\
\hline Female & ref & & & \\
\hline Male & $1.05(0.74-1.49)$ & 0.786 & - & - \\
\hline \multicolumn{5}{|l|}{ Race } \\
\hline AA & ref & & & \\
\hline White & $0.79(0.45-1.38)$ & 0.403 & - & - \\
\hline Other & $0.78(0.43-1.41)$ & 0.42 & - & - \\
\hline \multicolumn{5}{|l|}{$\mathrm{CCS}$} \\
\hline $0-4$ & ref & & & \\
\hline $5-9$ & $1.10(0.79-1.52)$ & 0.57 & - & - \\
\hline $10-14$ & $0.92(0.37-2.30)$ & 0.867 & - & - \\
\hline \multicolumn{5}{|l|}{ Cirrhosis } \\
\hline No & ref & & & \\
\hline Yes & $1.02(0.74-1.41)$ & 0.88 & - & - \\
\hline \multicolumn{5}{|c|}{ Chronic alcoholism } \\
\hline No & ref & & & \\
\hline Yes & $0.98(0.68-1.40)$ & 0.911 & - & - \\
\hline \multicolumn{5}{|c|}{ HBV infection } \\
\hline No & ref & & & \\
\hline Yes & $1.04(0.72-1.49)$ & 0.842 & - & - \\
\hline \multicolumn{5}{|c|}{$\mathrm{HCV}$ infection } \\
\hline No & ref & & & \\
\hline Yes & $0.83(0.60-1.16)$ & 0.272 & - & - \\
\hline \multicolumn{5}{|c|}{ Tumor size, $\mathrm{cm}$} \\
\hline$<5$ & ref & & ref & \\
\hline$>5$ & $1.52(1.12-2.06)$ & 0.007 & $1.27(0.88-1.85)$ & 0.20 \\
\hline \multicolumn{5}{|l|}{ Tümor grade } \\
\hline Well/Mod & ref & & & \\
\hline Poor/Undif & $1.21(0.83-1.76)$ & 0.31 & - & - \\
\hline \multicolumn{5}{|c|}{ Child-Pugh class } \\
\hline A & ref & & ref & \\
\hline $\mathrm{B}$ & $2.36(1.23-4.52)$ & 0.01 & $2.13(1.09-4.15)$ & 0.027 \\
\hline \multicolumn{5}{|c|}{ Type of resection } \\
\hline NAR & ref & & & \\
\hline $\mathrm{AR}$ & $1.16(0.79-1.70)$ & 0.46 & - & - \\
\hline \multicolumn{5}{|l|}{$\mathrm{AFP}, \mathrm{ng} / \mathrm{mL}$} \\
\hline$<20$ & ref & & ref & \\
\hline \multicolumn{5}{|l|}{$\mathrm{A} \overline{\mathrm{LT}}, \mathrm{U} / \mathrm{L}$} \\
\hline$<40$ & ref & & ref & \\
\hline$\geq 40$ & $1.60(1.14-2.25)$ & 0.007 & $1.53(1.05-2.23)$ & 0.027 \\
\hline GḠT, U/L & & & & \\
\hline$<64$ & ref & & & \\
\hline$\geq 64$ & $1.44(0.99-2.08)$ & 0.052 & - & - \\
\hline$\overline{\text { Pathologic lyn }}$ & phovascular invasic & & & \\
\hline No & ref & & ref & \\
\hline Yes & $1.82(1.31-2.54)$ & 0.001 & $1.48(1.01-2.18)$ & 0.044 \\
\hline Liver capsule & ivolvement & & & \\
\hline No & ref & & & \\
\hline Yes & $0.72(0.49-1.06)$ & 0.098 & - & - \\
\hline
\end{tabular}

$H R$ hazard ratio, $C I$ confidence interval, $A A$ African American, $C C S$ Charlson Comorbidity Score, $H B V$ hepatitis B virus, $H C V$ hepatitis $\mathrm{C}$ virus, $A R$ anatomical resection, $N A R$ non-anatomical resection, $A F P$ afetoprotein, $A L T$ alanine aminotransferase, $A S T$ aspartate aminotransferase, GGT gamma-glutamyl transferase Italics denote statistical significance 
who did not have lymphovascular invasion. Indeed, impaired liver function as determined by the Child-Pugh score has long been considered a strong determinant of long-term outcomes among patients undergoing liver resection for hepatobiliary malignancies. ${ }^{22}$ In addition, although no specific AFP cutoff level has been determined by the 8th AJCC staging manual to be associated with recurrence, higher preoperative AFP levels may indicate an aggressive tumor biology and, thus, may predict worse outcomes. ${ }^{25}$ To this point, AFP levels $\geq$ $20 \mathrm{ng} / \mathrm{mL}$ were associated with 1 higher hazards of recurrence among patients undergoing resection for T1 HCC. To this end, identifying patients at high risk of recurrence may be crucial in tailoring surveillance protocols or implementing adjuvant therapies that could be of benefit to high-risk patients. ${ }^{26}$

Patterns of HCC recurrence, including multicentric occurrence, intrahepatic metastasis, or local recurrence, have not been studied relative to surgical margin width. Of note, patterns of recurrence among patients who underwent a resection with wide versus narrow margins were similar (Table 2). In particular, the majority of recurrences were intrahepatic in both wide and narrow margin groups and most patients recurred in less than 24 months. ${ }^{12,}{ }^{27}$ Intrahepatic metastases likely occur early in the disease course, whereas multicentric occurrence is usually observed after a certain amount of time following hepatectomy for HCC. ${ }^{12,}{ }^{27}$ Interestingly, approximately $60 \%$ of intrahepatic recurrences are thought to occur close $(\leq 2.5 \mathrm{~cm})$ to the surgical margin. ${ }^{13}$ However, in the current study, local recurrence at the surgical margins was low in both groups $(<1 \mathrm{~cm} 7.1 \%$ vs $\geq 1 \mathrm{~cm} 4.8 \%, p=1.0)$. Although early recurrence could not be predicted by the resection margin width, the evidence supports a strong correlation between early recurrence and mesenchymal circulating tumor cells, which could be used as potential biomarkers in HCC monitoring following hepatectomy. ${ }^{28}$

Several limitations should be considered when interpreting the current study. The retrospective nature of the analysis may have introduced some selection biases. To limit patient selection bias, we restricted the analysis to only patients with $\mathrm{T} 1$ HCC such that the underlying clinicopathological characteristics between the wide and narrow margin groups were similar. As such, our results are applicable only to patients with $\mathrm{T} 1$ HCC. The number of patients in the non-anatomic group was also limited and, thus, further studies will need to corroborate the findings in this subset of patients. Data on neoadjuvant chemotherapy were not available; yet, it is highly unlikely that these patients received such treatment. In addition, the majority of the patients were treated at major tertiary referral centers and, therefore, the data may not be generalizable to the community setting.

In conclusion, wide resection margins $(>1 \mathrm{~cm})$ were associated with better RFS among patients undergoing R0 hepatectomy for early T1 HCC, especially small $(<5 \mathrm{~cm}) \mathrm{HCC}$. Certain factors, including Child-Pugh B liver function,
AFP $\geq 20$, and presence of microscopic lymphovascular invasion can help identify patients at high risk for recurrence. Irrespective of the margin width, most recurrences were intrahepatic and occurred early after hepatectomy. Although resection margins did not influence outcomes after anatomic resection, wider margins were more important for patients undergoing non-anatomic liver resections.

\section{Compliance with Ethical Standards}

The study was approved by the Institutional Review Boards of all participating institutions.

\section{References}

1. Torre LA, Bray F, Siegel RL, Ferlay J, Lortet-Tieulent J, Jemal A. Global cancer statistics, 2012. CA Cancer J Clin 2015;65:87-108.

2. Njei B, Rotman Y, Ditah I, Lim JK. Emerging trends in hepatocellular carcinoma incidence and mortality. Hepatology 2015;61:191-9.

3. European Association for the Study of the Liver. Electronic address eee, European Association for the Study of the L. EASL Clinical Practice Guidelines: Management of hepatocellular carcinoma. J Hepatol 2018;69:182-236.

4. Marrero JA, Kulik LM, Sirlin CB, et al. Diagnosis, Staging, and Management of Hepatocellular Carcinoma: 2018 Practice Guidance by the American Association for the Study of Liver Diseases. Hepatology 2018;68:723-50.

5. Lee JW, Lee YJ, Park KM, Hwang DW, Lee JH, Song KB. Anatomical Resection But Not Surgical Margin Width Influence Survival Following Resection for HCC, A Propensity Score Analysis. World J Surg 2016;40:1429-39.

6. Chau GY, Lui WY, Tsay SH, et al. Prognostic significance of surgical margin in hepatocellular carcinoma resection: an analysis of 165 Childs' A patients. J Surg Oncol 1997;66:122-6.

7. Chen MF, Tsai HP, Jeng LB, et al. Prognostic factors after resection for hepatocellular carcinoma in noncirrhotic livers: univariate and multivariate analysis. World J Surg 2003;27:443-7.

8. Shi M, Guo RP, Lin XJ, et al. Partial hepatectomy with wide versus narrow resection margin for solitary hepatocellular carcinoma: a prospective randomized trial. Ann Surg 2007;245:36-43.

9. Lazzara C, Navarra G, Lazzara S, et al. Does the margin width influence recurrence rate in liver surgery for hepatocellular carcinoma smaller than $5 \mathrm{~cm}$ ? Eur Rev Med Pharmacol Sci 2017;21:523-9.

10. Zhong FP, Zhang YJ, Liu Y, Zou SB. Prognostic impact of surgical margin in patients with hepatocellular carcinoma: A meta-analysis. Medicine (Baltimore) 2017;96:e8043.

11. Sakon M, Nagano H, Nakamori S, et al. Intrahepatic recurrences of hepatocellular carcinoma after hepatectomy: analysis based on tumor hemodynamics. Arch Surg 2002;137:94-9.

12. Famularo S, Di Sandro S, Giani A, et al. Recurrence Patterns After Anatomic or Parenchyma-Sparing Liver Resection for Hepatocarcinoma in a Western Population of Cirrhotic Patients. Ann Surg Oncol 2018;25:3974-81.

13. Kumar AM, Fredman ET, Coppa C, El-Gazzaz G, Aucejo FN, Abdel-Wahab M. Patterns of cancer recurrence in localized resected hepatocellular carcinoma. Hepatobiliary Pancreat Dis Int 2015;14: 269-75.

14. Lee KT, Wang SN, Su RW, et al. Is wider surgical margin justified for better clinical outcomes in patients with resectable hepatocellular carcinoma? J Formos Med Assoc 2012;111:160-70. 
15. Lafaro K, Grandhi MS, Herman JM, Pawlik TM. The importance of surgical margins in primary malignancies of the liver. J Surg Oncol 2016;113:296-303.

16. Field WBS, Rostas JW, Philps P, Scoggins CR, McMasters KM, Martin RCG, II. Wide versus narrow margins after partial hepatectomy for hepatocellular carcinoma: Balancing recurrence risk and liver function. Am J Surg 2017;214:273-7.

17. Spolverato G, Yakoob MY, Kim Y, et al. The Impact of Surgical Margin Status on Long-Term Outcome After Resection for Intrahepatic Cholangiocarcinoma. Ann Surg Oncol 2015;22: 4020-8.

18. Pawlik TM, Gleisner AL, Vigano L, et al. Incidence of finding residual disease for incidental gallbladder carcinoma: implications for re-resection. J Gastrointest Surg 2007;11:1478-86; discussion 86-7.

19. Dong S, Wang Z, Wu L, Qu Z. Effect of surgical margin in R0 hepatectomy on recurrence-free survival of patients with solitary hepatocellular carcinomas without macroscopic vascular invasion. Medicine (Baltimore) 2016;95:e5251.

20. Moris D, Rahnemai-Azar AA, Tsilimigras DI, et al. Updates and Critical Insights on Glissonian Approach in Liver Surgery. J Gastrointest Surg 2018;22:154-63.

21. Moris D, Tsilimigras DI, Kostakis ID, et al. Anatomic versus nonanatomic resection for hepatocellular carcinoma: A systematic review and meta-analysis. Eur J Surg Oncol 2018;44:927-38.

22. Goh BK, Chow PK, Teo JY, et al. Number of nodules, Child-Pugh status, margin positivity, and microvascular invasion, but not tumor size, are prognostic factors of survival after liver resection for mul- tifocal hepatocellular carcinoma. J Gastrointest Surg 2014;18: $1477-85$.

23. Hanazaki K, Kajikawa S, Shimozawa N, et al. Survival and recurrence after hepatic resection of 386 consecutive patients with hepatocellular carcinoma. J Am Coll Surg 2000;191:381-8.

24. Moris D, Chakedis J, Sun SH, et al. Management, outcomes, and prognostic factors of ruptured hepatocellular carcinoma: A systematic review. J Surg Oncol 2018;117:341-53.

25. Notarpaolo A, Layese R, Magistri P, et al. Validation of the AFP model as a predictor of HCC recurrence in patients with viral hepatitis-related cirrhosis who had received a liver transplant for HCC. J Hepatol 2017;66:552-9.

26. Cloyd JM, Pawlik TM. Adjuvant Therapy for Biliary Tract Cancers: New Evidence to Resolve Old Questions. J Oncol Pract 2018;14:723-4

27. Zhou L, Rui JA, Wang SB, Chen SG, Qu Q. Early recurrence in large hepatocellular carcinoma after curative hepatic resection: prognostic significance and risk factors. Hepatogastroenterology 2014;61:2035-41.

28. Wang Z, Luo L, Cheng Y, et al. Correlation Between Postoperative Early Recurrence of Hepatocellular Carcinoma and Mesenchymal Circulating Tumor Cells in Peripheral Blood. J Gastrointest Surg 2018;22:633-9.

Publisher's Note Springer Nature remains neutral with regard to jurisdictional claims in published maps and institutional affiliations. 